\title{
An electromyographic examination of response competition
}

\author{
CHARLES W. ERIKSEN, MICHAEL G. H. COLES, L. R. MORRIS, and WILLIAM P. O'HARA \\ University of Illinois at Urbana-Champaign, Champaign, Illinois
}

\begin{abstract}
Subjects were required to discriminate the letters $\mathrm{S}$ and $\mathrm{H}$ in a choice reaction time task. They responded with a thumbpress of one hand to one of the letters and with the thumb of the other hand to the other letter. In the incompatible noise condition, the target letter was flanked by the opposite response letter, and in the compatible noise condition, the flanking noise letters were identical to the target. In addition to overt reaction time, associated electromyographic activity was recorded in both arms on each trial. In keeping with previous findings, incompatible noise significantly and appreciably increased reaction time for the overt response. More importantly, in the incompatible condition, the occurrence of a correct thumb response was frequently accompanied by an EMG in the arm appropriate to the noise letters. This result was interpreted as showing that the noise letters were processed to the point of incipient response activation simultaneously with the target letter. The results were predicted by the continuous flow model of C. W. Eriksen and Schultz (1979) and the variable criterion theory of Grice, Nullmeyer, and Spiker (1982).
\end{abstract}

Response competition has been employed as an explanatory construct to account for observed increases in reaction time (RT) in situations in which elements in the stimulus activate two or more different responses. It is assumed that the simultaneous activation of different responses results in mutual inhibition of these responses, thus delaying their execution. One of the better known examples is the Stroop effect. Here, the latency in naming an ink color is delayed if the color material is presented in the form of a word that refers to a different color name (Stroop, 1935). More recently, Proctor (1981) used the construct of response competition to account for the frequent finding on matching tasks that judgments of "different" have longer latencies than judgments of "same." The different stimuli are presumed to result in the simultaneous activation of two different name codes that mutually inhibit each other.

Stroop-like interference effects have been found to occur on a wide variety of tasks (B. A. Eriksen \& C. W. Eriksen, 1974; C. W. Eriksen, B. A. Eriksen, \& Hoffman, in press; Keren, O'Hara, \& Skelton, 1977; Shaffer \& LaBerge, 1979). B. A. Eriksen and C. W. Eriksen (1974) studied the effects of surrounding noise letters upon choice RT to target letters. Subjects' RTs were substantially greater when the centrally located target letter was surrounded by letters of the opposite response set than when the target and noise letters were from the same response set. Also, neutral noise letters (letters from

\footnotetext{
This research was supported in part by Public Health Service Research Career Program Award K6-MH-22014 to the first author, by Public Health Service Research Grant MH 01206, and by AFOSR Contract F 49620-83-C-0144, Al Fregly, Project Manager. The authors' mailing address is: Department of Psychology, University of Illinois at UrbanaChampaign, Champaign, IL 61820.
}

neither response set) produced intermediate effects that were a function of the featural overlap they shared with either response set. These results were interpreted as showing not only that subjects are unable to completely restrict their attention to the target item, but also that since RTs could be manipulated as a function of the experimentally defined target-noise response compatibilities, the noise items must have been processed along with the target items at least to the point of incipient response activation.

Such response competition effects are difficult to reconcile with discrete stage models of visual information processing (Sternberg, 1969) that assume that information is processed serially through stages from input through decision stage. The decision stage culminates in response activation. Each stage is assumed to complete processing of the stimulus before the next stage begins. Although both target and noise stimuli could conceivably pass through the processing stages simultaneously, a discrete decision stage that activates responses would presumably prevent the incorrect response from gaining access to the motor pathways.

Response competition effects are more easily assimilated by continuous processing models such as the continuous flow model of C. W. Eriksen and Schultz (1979) or the variable criterion model of Grice, Nullmeyer, and Spiker (1982). Both of these models posit that information accumulates or develops gradually over time. During this development, the information is passed continuously through the different stages and results in the priming of relevant responses. This gradual priming of responses as the information is being processed leads to a prime or partial activation of competing responses when the stimulus contains noise stimuli appropriate to these responses. Thus, when the criterion is reached for the cor- 
rect response to a target, the response must be executed against a background of partial activation of other responses. It is assumed that this partial activation of competing responses delays the execution of the correct response.

The locus of response competition effects in terms of partial activation of alternative or competing responses would be greatly supported, as would also continuous flow models of information processing, if evidence could be obtained showing that the alternative response system is indeed incipiently activated or primed. In the present experiment, we looked for evidence of the incipient activation of competing responses by examining electromyographic activity. The response competition paradigm of B. A. Eriksen and C. W. Eriksen (1974) was used. In this paradigm, the subject is required to classify a target letter that is surrounded by noise letters that require a response different from the target response. Even though the subject executes the correct response, we anticipated there might be electromyographic indications that the response appropriate to the noise letters was also incipiently activated.

\section{METHOD}

\section{Procedure}

On each trial of the experiment, the subject was required to identify which of two target letters (H or S) appeared briefly in the centrally designated target position of a tachistoscopic display. There were two types of displays: (1) The target and surrounding noise letter were identical and response compatible ( $\mathrm{H} \underline{\mathrm{H}} \mathrm{H}$ and $\mathrm{S} S \mathrm{~S}$ ); and (2) the surrounding noise letters were response incompatible with the target letter (H S H and S H S). The subject identified the target letters by pressing separate response buttons with either the right or left thumb. An electromyogram (EMG) was recorded from the flexor of each arm.

After fixating a small cross in the center of the visual field, the subject initiated a trial with a footpress. Immediately thereafter, the fixation field was replaced with a blank field for $150 \mathrm{msec}$, which was followed, in turn, by the stimulus field, which remained on for $150 \mathrm{msec}$, and then the fixation field reappeared. All the subjects were instructed to respond only on the basis of the center letter that occurred immediately above the fixation point. They were to ignore the noise letters. After each trial, RT feedback was provided.

Each subject participated in only one session lasting about $90 \mathrm{~min}$. Before data were collected, each subject had a practice period during which 40 mixed-condition trials were run. Following this warmup, each subject received five blocks of 40 trials. Each block consisted of 10 randomly ordered presentations of each of the four stimulus displays.

\footnotetext{
Apparatus and Stimuli

The stimuli were presented in a Scientific Prototype three-channel tachistoscope. Luminances of the white background for all fields were set at $30 \mathrm{~cd} / \mathrm{m}^{2}$. RTs were recorded to the nearest millisecond on a Hunter Model 1522 digital clock counter. The stimuli were the capital leters $\mathrm{H}$ and $\mathrm{S}$, which appeared against a white vinyl card background. They were Zipatone Futura Bold 20 point; at the experimental viewing distance, they subtended $.21^{\circ}$ and $.19^{\circ}$ of visual angle in height and width, respectively. The three-letter display subtended $.73^{\circ}$ of visual angle, with a between-letter spacing of $.08^{\circ}$ of visual angle edge to edge.

An EMG was recorded from the flexor muscles of each hand with Beckman silver/silver-chloride electrodes (5 $\mathrm{mm}$ in diameter), using the forearm flexor placement described by Lippold (1967). Recordings were on Beckman R-411 dynagraph. Amplitude settings varied between subjects but were constant within subjects. They were adjusted to yield pen deflections approximately $2 \mathrm{~cm}$ for a buttonpress response. An EMG
}

response in either hand was scored if the EMG trace following stimulus onset was greater than $5 \mathrm{~mm}$ above baseline activity. If EMG activity meeting this criterion occurred only in the muscles associated with one hand, the trial was classified as a single EMG trial. When the criterion activity occurred in the muscles associated with both hands, the trial was classified as a dual EMG trial.

\section{Subjects}

Three of the experimenters and two student volunteers (paid) served as subjects. Each had either normal or corrected-to-normal vision.

\section{RESULTS AND DISCUSSION}

Consistent with previous research (B. A. Eriksen \& C. W. Eriksen, 1974; C. W. Eriksen \& B. A. Eriksen, 1979), the response latency for the buttonpress was significantly longer $[\mathrm{t}(4)=6.89, \mathrm{p}<.01]$ when the target letter was flanked by incompatible noise letters than when it was flanked by repetitions of itself (compatible noise). RTs averaged $85 \mathrm{msec}$ faster for the compatible noise displays ( 582 vs. $667 \mathrm{msec}$ ). This difference could not be attributed to speed-accuracy trade-offs, since the error rate for the incompatible target noise condition (15\%) was greater than that for the compatible noise condition (5\%).

Our major interest, however, concerns the relationship between trials on which EMGs revealed activity evident in both hands and the type of target-noise compatibility. Criterion EMG responses were observed in both hands on $40 \%$ of the trials when the target and noise were incompatible versus $8 \%$ of the trials when target and noise were compatible. The difference between these percentages is significant $(p<.05)$, with all subjects showing substantially more dual EMG responses on incompatible trials than on compatible trials.

In Figure 1, buttonpress latencies and EMG latencies to compatible and incompatible displays are shown separately for those trials on which the criterion EMG response was obtained only in the correct arm and for those trials in which an EMG occurred in both arms. These data are for those trials on which a correct buttonpress response was executed. However, the latency of the incorrect EMG on the dual EMG trials is also shown in the dual EMG graph. Note that these incorrect EMGs measure only the initiation of motor activity, which did not result in a completed or detectable buttonpress response.

As is seen in Figure 1, the latency of the correct buttonpress response is considerably greater when there is EMG activity present in the incorrect hand. This is true for both compatible and incompatible displays, although the value for compatible displays with dual EMG activity is unstable due to the low number of trials in this category $(8 \%)$. If we eliminate those trials in which EMG activity occurred in the incorrect hand, there is still a 40-msec difference in latency for incompatible versus compatible displays for the buttonpress response $(p<.05)$. This residual difference may be due to the fact that there are response competition effects that are too subtle to be detected by EMG activity or are below our criterion for scor- 


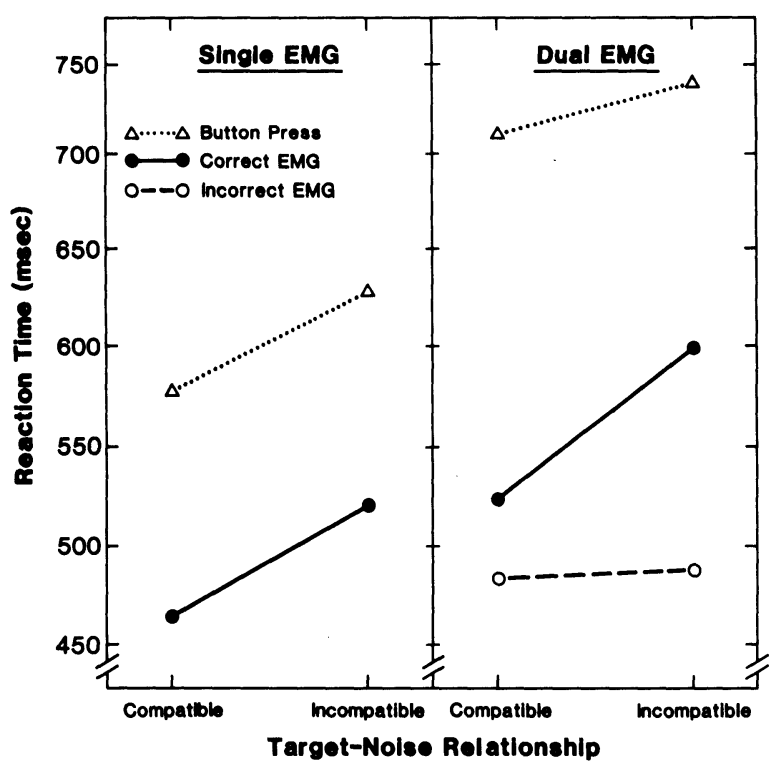

Figure 1. Mean latencies of buttonpress and EMG activity as a function of noise compatibility for those trials on which EMG activity occurred in only the "correct" arm (single EMG) and those trials on which EMG activity was present in both arms (dual EMG).

ing EMG activity. It is quite possible that competition occurs at preparatory leyels in terms of postural adjustments that are not reflected in the final link of the response. Also, competition may exist at the recognition level (C. W. Eriksen \& Schultz, 1979; Proctor, 1981). Furthermore, we cannot exclude the possibility that there are also interference effects at the input level of processing (Flowers \& Wilcox, 1982; Grice, Canham, \& Shafer, 1982).

For those $8 \%$ of the trials on which EMG activity occurred in the incorrect hand with compatible noise, factors other than stimulus-driven competition must be responsible. One factor may be that the subject is momentarily confused about response mappings, and another might be occasional guessing strategies. That they are different from stimulus-driven competition effects is suggested by two other features of the data. The first is seen in a comparison of the difference between the correct EMG latency and the occurrence of the overt buttonpress response. This latency difference varies from 104 to $118 \mathrm{msec}$ for compatible and incompatible displays in the single EMG response trials and in the incompatible displays on the dual EMG response trials. In contrast, there is 133-msec difference between EMG latency and buttonpress latency for the compatible trials when incorrect EMG activity occurs. Although the difference is not significant, it does suggest that when incorrect EMG is present for a compatible display, it is due to variables other than response competition. This interpretation is further supported when the latency of the incorrect EMG activity is examined. Latency is essentially identical for both compatible and incompatible displays, but with compatible displays it precedes the correct EMG latency by only $51 \mathrm{msec}$, whereas, for incompatible displays, the incor- rect EMG activity leads correct EMG activity by $140 \mathrm{msec}$. The difference between these differences is significant $(\mathrm{p}<.05)$.

The present experiment differed from previous response competition studies in that the signifying responses for the target and for incompatible noise were not "structurally" incompatible. By this we mean, in the present instance, both responses could be executed simultaneously. In previous studies (B. A. Eriksen \& C. W. Eriksen, 1974; C. W. Eriksen \& B. A. Eriksen; C. W. Eriksen \& Hoffman, 1973), the signifying responses were such that they could not be performed simultaneously. One cannot voice two letters or two colors simultaneusly or move a response lever both right and left at the same time. Our present finding of an appreciable response competition effect suggests that the effect does not depend upon "structural" response incompatibility. Apparently, responses can compete at stages that precede actual response execution. Preparation to make one response impedes the execution of another response even though both responses would appear capable of execution at the same time. It is also possible that the need to inhibit the incorrect response from overt expression may spread inhibition to the correct response, which slows its execution.

\section{SUMMARY}

The results of this experiment are quite clear in showing that competition between responses is a viable explanation for the impaired performance observed in the presence of competing stimuli. The data support the variable criterion model of Grice, Nullmeyer, and Spiker (1982) and the continuous flow model of C. W. Eriksen and Schultz (1979). They also pose serious problems for simple discrete stage models that conceive of the decision stage's acting upon the product of processing by activating an appropriate response. At the very least, discrete stage models would need to consider a vacillating or leaky decision stage that is unable to make a clean decision between the relevant and the irrelevant stimuli processed. In activating the correct response, some activation apparently would have to spill over and partially activate the inappropriate response associated with the noise stimuli. Alternatively, one might try to account for the results by assuming that on a certain proportion of trials, the noise stimuli finish processing before the target and the decision stage begins to activate the response appropriate to the noise but aborts this activation when the target stimulus arrives from the prior processing. This possibility seems unlikely in view of the differences that we noted between dual EMG activity to compatible displays as opposed to the incompatible ones. On the few trials on which incorrect EMG activity occurred for compatible displays, the latency between the incorrect EMG and the correct EMG was appreciably shorter than the comparable latency difference for incompatible displays. This would suggest that the correction is made much faster in the absence of competing stimuli. When dual EMGs occurred for compatible displays, this would most likely be comparable to the situation in which a decision stage activated the wrong response and then had to abort. Our data suggest that this type of abortion occurs with a shorter latency than is observed when an incorrect response is primed by the noise stimuli in the display.

\section{REFERENCES}

EriKsen, B. A., \& EriKsen, C. W. (1974). Effects of noise letters on the identification of a target letter in a nonsearch task. Perception \& Psychophysics, 16, 143-149.

Eriksen, B. A., Eriksen, C. W., \& Hoffman, J. E. (in press). Recognition memory and attentional selection: Serial scanning is not enough. Perception \& Psychophysics. 
Eriksen, C. W., \& Eriksen, B. A. (1979). Target redundancy in visual search: Do repetitions of the target within the display impair processing? Perception \& Psychophysics, 26, 195-205.

Eriksen, C. W., \& Hoffman, J. E. (1973). The extent of processing of noise elements during selective encoding from visual displays. Perception \& Psychophysics, 14, 155-160.

ERIKSEN, C. W., \& SCHUlTz, D. W. (1979). Rate of information processing in visual search: A continuous flow conception and experimental result. Perception \& Psychophysics, 25, 249-263.

FLOWERS, J. H., \& WiLCOX, N. (1982). The effect of flanking context on visual classification: The joint contribution of interactions at different processing levels. Perception \& Psychophysics, 32, 581-591.

Grice, G. R., Canham, L., \& Shafer, C. (1982). Development of associative and perceptual interference. Perception \& Psychophysics, 32, 375-387.

Grice, G. R., Nullmeyer, R., \& SPIKeR, V. A. (1982). Human reaction time: Toward a general theory. Journal of Experimental Psychology: General, 11, 135-153.
Keren, G., O'Hara, W. P., \& Skelton, J. (1977). Levels of noise processing and attentional control. Journal of Experimental Psychology: Human Perception \& Performance, 3, 653-664.

LiPPoLD, O. C. J. (1967). Electromyography. In P. H. Venables \& I. Martin (Eds.), A manual of psychophysiological methods (pp. 245297). Amsterdam: North-Holland.

Proctor, R. W. (1981). A unified theory for matching-task phenomena. Psychological Review, 88, 291-326.

ShaFFER, W. O., \& LABERGE, D. (1979). Automatic semantic processing of unattended words. Journal of Verbal Learning and Verbal Behavior, 18, 413-426.

STERNBERG, S. (1969). Memory scanning: Mental processes revealed by reaction time experiments. American Scientist, 57, 421-457.

STROOP, J. R. (1935). Studies of interference in serial verbal reactions. Journal of Experimental Psychology, 18, 643-662.

(Manuscript received for publication January 25, 1985.) 